\title{
New Procedure of Connective Tissue Staining and Its Application to the Liver Diagnosis in Histologic Sections
}

\author{
By \\ Masachika SENBA \\ Department of Pathology, Institute for Tropical Medicine, Nagasaki University, \\ Nagasaki 852, Japan
}

-Received for Publication, March 12, 1984 -

\begin{abstract}
Key Words: Connective tissue, Hepatitis B surface antigen, Liver diagnosis, Orcein, Aniline blue

Summary: This method can detect hepatitis B surface antigen, copper-associated protein, elastic fibers and collagen fibers by orcein and aniline blue dyes. As a result, this new procedure can lead to a better understanding of the liver diseases on the one slide glass. The method is useful not only for liver tissue but also for connective tissue as well.
\end{abstract}

The author has previously reported hepatitis B surface antigen staining method (Senba 1982a, b) and new differentiating solution for hepatitis B surface antigen (Senba 1983). The author considered that if elastic fibers as well as collagen fibers are stained by orcein dye on the one slide glass, hepatic fibrosis will be understood well. The author tried to modify the orcein method and found that the procedure using an aniline blue after orcein staining gave stable and satisfactory results.

Elastic fibers and collagen fibers are detected in histologic sections by the orcein dye, as reported by Unna (1890) and Lillie (1968). The purpose of this paper is to present a new procedure to establish a more distinguishable staining method for elastic fibers and collagen fibers using orcein dye.

\section{Materials and Methods}

The liver specimens from autopsy cases and biopsy cases of various liver diseases, including acute hepatitis, chronic active hepatitis, chronic inactive hepatitis, hepatocellular carcinoma without cirrhosis, hepatocellular carcinoma with cirrhosis and cirrhosis at Nagasaki University Medical School were performed. Most of the materials were fixed in formalin, a few materials were fixed in Zenker's formol, embedded in paraffin and cut routinely.

The steps involved in staining method for connective tissue and its application to the liver diagnosis are the following: (1) Deparaffinize and hydrate to distilled water. (2) Treat with oxidize solution for $5 \mathrm{~min}$ utes. Oxidize solution: In $100 \mathrm{ml}$ of distilled water, dissolve $0.3 \mathrm{~g}$ potassium permanganate and $0.3 \mathrm{ml}$ sulfulic acid. (3) Wash in running water. (4) Treat with $2 \%$ oxalic acid solution until sections become clear. (5) Wash in running water. (6) Treat with the sensitizer solution for 1 minute. Sensitizer solution: $2 \%$ ferric ammonium sulfate solution (or $1 \%$ uranium nitrate solution). (7) Wash in running water. (8) Treat with 
the orcein solution for 5-10 minutes. Orcein solution: In $100 \mathrm{ml}$ of $70 \%$ alcohol, dissolve $1 \mathrm{~g}$ orcein (Merck, Art. 7091, Lot. 8529084 ) and $1.2 \mathrm{ml}$ hydrochloric acid. The supernatant is available in 2-3 days. (9) Differentiate with absolute alcohol. (10) Differentiate with absolute alcohol containing $1 \%$ hydrochloric acid solution for 5 minutes. (11) Differentiate with new differentiating solution, if necessary. New differentiating solution: Dissolve $0.02 \mathrm{~g}$ EDTA-2Na or EDTA (ethylenediaminetetraacetic acid) and add $1 \mathrm{ml}$ hydrochloric acid in $100 \mathrm{ml}$ of $80-100 \%$ alcohol. (12) Wash in running water. (13) Perform nuclear stain in Weigert's iron hematoxylin for 5 minutes. (14) Wash in running water. (15) Differentiate with $1 \%$ hydrochloric acid solution. (16) Wash in running water. (17) $5 \%$ phosphotungstic acid or $1 \%$ phosphomolybdic acid for 30 minutes to one hour. (18) Wash in running water. (19) Treat with the aniline blue for 3 to 5 minutes. Aniline blue solution: In $100 \mathrm{ml}$ of distilled water, dissolve $0.5 \mathrm{~g}$ aniline blue water solble (Merck, Art. 1279, Lot. 6380) and add $5 \mathrm{ml}$ acetic acid. (20) Wash in running water. (21) Dehydrate, clear and mount.

\section{Results}

Collagen fibers were stained blue. In chronic liver diseases, however, and especially in cirrhosis, this connective tissue, particularly the collagen component, markedly increases. Hepatic fibrosis is greatly responsible for many of the sequelae of chronic liver diseases, for instance virus hepatitis, alcoholism, prolonged cholestasis, cardiac failure, hepatic venous obstruction, hemochromatosis, hepato-lenticular degeneration (Wilson's disease), fibrocystic diseases, galactosaemia, congenital syphilis and schistosomiasis (Sherlock 1968, Schiff and Schiff 1982). Thus, in the transition from chronic active hepatitis to cirrhosis, fibrosis is a key process. Thereby, this method is useful for liver tissue sections. Hepatitis B surface antigen were stained brown. Recently non-A, non-B hepatitis is quite interesting liver diseases. Histologic staining method for hepatitis B surface antigen is useful in diagnosis of non- $A$, non-B hepatitis because diagnosis of non- $A$, non- $B$ hepatitis can only be made by ruling out the presence of other viral agents, including hepatitis B virus, hepatitis A virus, cytomegalovirus, herpes simplex virus, and Epstein-Barr virus. Therefore, for histologic diagnosis, hepatitis B surface antigen staining are useful not only for hepatitis B surface antigen but also for non-A, non-B hepatitis. Most of the copper-associated proteins were stained brown, a few copper-associated proteins were stained blue to bluish brown, and these materials concern primary biliary cirrhosis and cholestatic liver diseases (Salaspuro et al. 1976a, b, c, Sipponen et al. 1975, Sipponen 1976a, b, Nakanuma et al. 1979). Elastic fibers and bile pigment were stained brown. Erythrocytes, mast cells, degenerative and necrotic cytoplasms were not stained. Nuclei were stained black (Fig. 1).

\section{Discussion}

Interpretation of the reaction of phosphotungstic acid and phosphomolybdic acid are described in the following. If these metal salts of the step 17 were not used, the tissue sections were stained blue all over the sections by aniline blue dye. The author considered that the action of metal salts masked tissue sections except for connective tissue. Generally metal salts are positively charged in the solution (Basolo and Pearson 1967). However, tungsten and molybden metal salts are negatively charge in the solution (Cotton 
and Wilkinson 1980). In the reaction in which amino groups react with hydrogen in an acidic solution $\left({ }^{+} \mathrm{NH}_{3}-\mathrm{R}-\mathrm{COOH}\right)$ the electric charge of proteins becomes positive as a result. Therefore, protein reacts with negatively charged metal because of coupling of the electric charge.

Compared with light green SF (Merck, Art. 1315, Lot. 5902285), aniline blue detected minor collagen fibers well.

\section{Acknowledgements}

The author wishes to thank Prof. Takao Setoguti, Prof. Hideo Tsuchiyama, Associate Prof. Yutaka Okumura, Associate Prof. Kiyoko Kawai and Dr. Hidekatsu Matsumura for critically reading the manuscript. Gratitude is also due to Prof. Hideyo Itakura.

\section{Literature Cited}

1) Basolo, R. and Pearson, R. G.: Mechanism of Inorganic Reaction: A Study of Metal Complexes in Solution. 2nd ed. pp. 454-525. John Wiley and Sons, Inc., New York, 1967.

2) Cotton, F. A. and Wilkinson, G.: Advanced Inorganic Chemistry. 4th ed. pp. 844-883. John Wiley and Sons, Inc., New York, 1980.

3) Lillie, R. D., Gutierrez, A., Madden, D. and Henderson, R.: Acid orcein-iron and acid orcein-copper stains for elastin. Stain Technol., 43: 203-206, 1968.

4) Nakanuma, Y., Karino, T. and Ohta, G.: Orcein positive granules in the hepatocytes in chronic intrahepatic cholestasis. Virchows Arch. A, 382: 21-30, 1979.

5) Salaspuro, M. P. and Sipponen, P., Ikkala, E., Kolho, L., Makkonen, H. M., Miettinen, T. A., Räsänen, J. A. and Siurala, M.: Clinical correlations and significance of orcein-positivity in chronic active hepatitis and primary biliary cirrhosis. Ann. Clin. Res., 8: 206-215, 1976 a.

6) Salaspuro, M. P. and Sipponen, P.: Demonstration of an intracellular copper-binding protein by orcein staining in long-standing cholestatic liver diseases. Gut, 17: 787-790, 1976b.

7) Salaspuro, M. P., Sipponen, P. and Makkonen, H. M.: The occurrence of orcein-positive hepatocellular material in various liver diseases. Scand. J. Gastroenterol., 11: 677-687, $1976 \mathrm{c}$.

8) Schiff, L. and Schiff, E. R.: Diseases of the Liver. 5th ed. pp. 847-977. J. B. Lippincott Company, Philadelphia, 1982.

9) Senba, M.: Staining method for hepatitis B surface antigen (HBs Ag) and its mechanism. Am. J. Clin. Pathol., 77: 312-315, 1982a

10) Senba, M.: The author's reply; Response to the letter to the editor on "Staining method for hepatitis B surface antigen (HBs Ag) and its mechanism" by Olson, A.L. Am. J. Clin. Pathol., 78: 573, 1982b.

11) Senba, M.: New differentiating solution for hepatitis B surface antigen staining method. Am. J. Clin. Pathol., 79: 647-648, 1983.

12) Sherlock, S.: Diseases of the Liver and Biliary System. 4th ed. pp. 395-436. Blackwell Scientific Publications, Philadelphia, 1968.

13) Sipponen, P., Salaspuro, M. P. and Makkonen, H. M.: Orcein positive hepatocellular material in histological diagnosis of primary biliary cirrhosis. Ann. Clin. Res., 7: 273-277, 1975.

14) Sipponen, P.: Orcein positive hepatocellular material in long-standing biliary diseases-I. Histochemical characteristics. Scand. J. Gastroenterol., 11: 545-552, 1976a.

15) Sipponen, P.: Orcein positive hepatocellular material in long-standing biliary diseases-II. Ultrastructural studies. Scand. J. Gastroenterol., 11 : 553-558, $1976 \mathrm{~b}$.

16) Unna, P. G.: Notiz betreffend die Taenzershe Orceinfärbung des elastischen Gewebes. Monatsch prakt Dermatol., 12: 394-396, 1890. 


\section{Explanation of Figure}

\section{Plate I}

Fig. 1. The inclusion type of hepatitis B surface antigen was stained in the liver cells. Fibrosis are seen surrounding the central vein (center). (Orcein and aniline blue stain, $\times 400$.) 


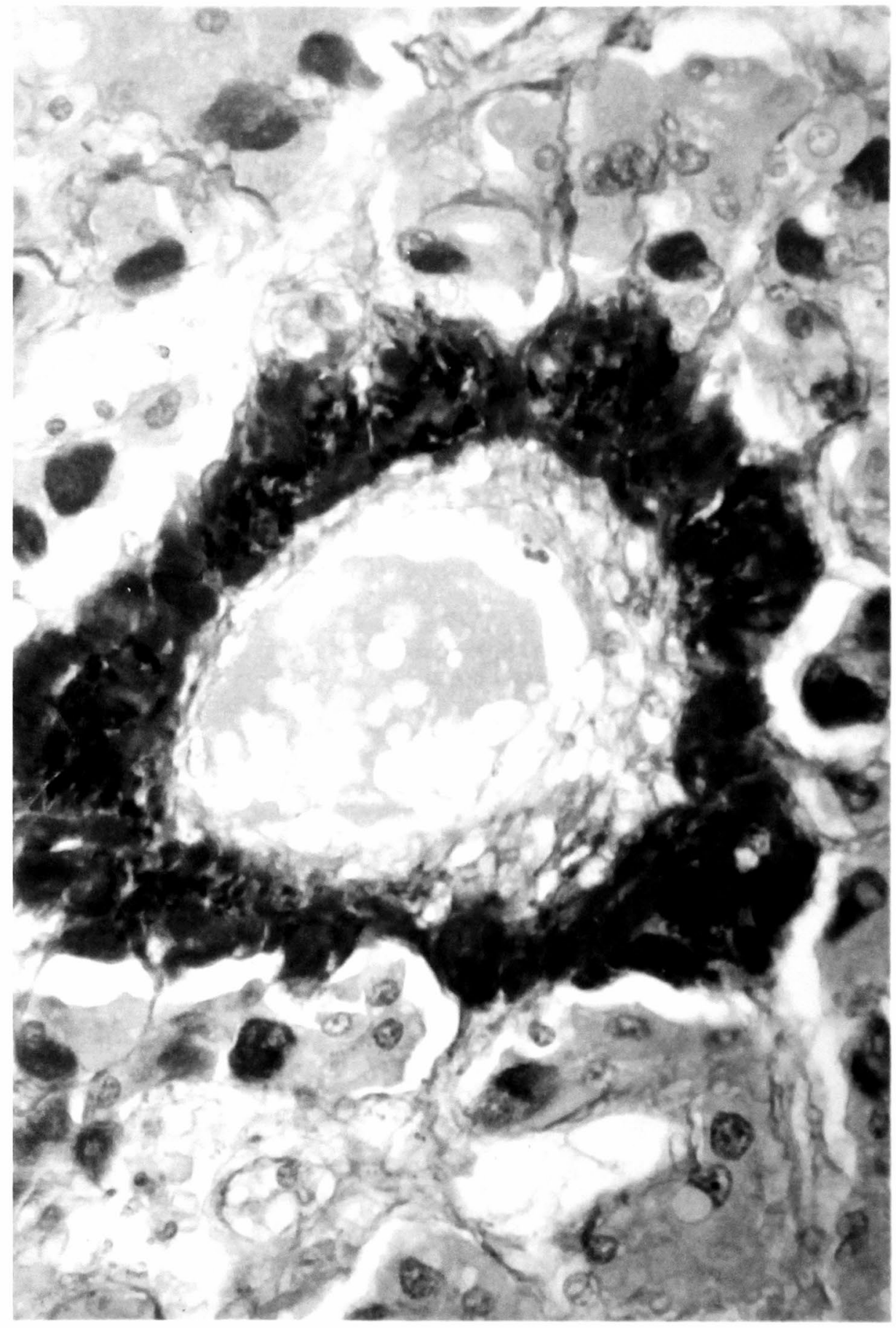

